\title{
Editorial
}

\section{Architectural Competitions II The dynamics of competing and organising competitions in architecture and urban design}

\section{Editor's Comments}

In this issue, we present three papers that discuss competitions in architecture and urban design. The papers were initially presented at the International conference Architecture as Human Interface in Helsinki, 26-27 October 2012. The conference was organised by the Finnish Association of Architects, together with the departments of architecture at the Aalto University, Oulu University and Tampere University of Technology, the Department of Construction at Novia University of Applied Sciences, Finland and KTH/Architecture, Sweden. Kimmo Lapintie, Professor at Aalto University, closed the conference, and summarised it by the formulation of a four-point statement, The Helsinki declaration on Architectural Research. The declaration forwards creativity and criticism as the fundaments for architectural research.

The Helsinki conference had two main aims. Firstly, the intention was to present and discuss contemporary architectural research on architectural competitions in an international context. Secondly, the conference was part of a long-term development of an international research network that focuses on the architectural competition as a common scientific object and special field of knowledge production. For this reason, the conference included a special session with 20 papers that highlighted aspects of competitions in architecture and urban design. After a blind review process with two external reviewers per paper, seven articles were selected for two special issues of the journal of FORMakademisk, called Architectural Competitions I, Exploring the phenomenon of competing in architecture and urban design and Architectural Competitions II, The dynamics of competing and organising competitions in architecture and urban design.

In retrospect, the development of an international network for research on competitions began in 2008 when the School of Architecture and the Built Environment, Royal Institute of Technology $(\mathrm{KTH})$, organised the first scientific conference on architectural competition in Stockholm. In 2010, a second scientific conference took place at Copenhagen Business School in Denmark as part of the full conference Constructions Matter; Managing Complexities, Decisions and Actions in the Building Process. The third international conference, Competitions and Architectural Quality in the Planetary Age, was held in Montreal, Canada in 2012. The fourth fol- 
lowed shortly with the conference in Helsinki. The upcoming conference on architectural competitions will be the fifth international, Conditions for Client-Architect interaction, which will take place in Delft in 2014, The Netherlands.

The three papers in this special issue of FORMakademisk; Architectural Competitions II, The dynamics of competing and organising competitions in architecture and urban design discuss the competition processes in a dual perspective, either the one of the client or the organiser or as seen by the jury and competing design teams. These actors are key players in the competition process. The papers in this issue will refer to the competition as consecutive steps in a decision-making process with aesthetical and architectural features. This process starts with the client's or the organizer's invitation to the body of architects to take part in competitions. The ultimate aim of this invitation is the client's or organiser's selection of design teams. However, such an invitation is always met with serious considerations by architectural firms in order to align their application with the design problems at stake. The last paper presents a different kind of competition, the developer competition, and how this competition form is implemented in Finland. This is a new type of competition in architecture and urban design, which is organised by the public sector, and, currently, increasingly in use. Nowadays in Finland and Sweden, developer competitions constitute a successful alternative to the traditional architectural competitions, approved by the national architects' associations. A fair question can be posed: is this type of competition a threat for the body of architects or merely a gimmick to introduce certain design quality in a more market-oriented process of planning new urban areas?

Associate professor Magnus Rönn, Royal Institute of Technology, KTH, opens the discussion with a study on the client's/ organiser's selection of architectural firms in ten invited and, hence, restricted competitions, in Sweden, organised from 2007 to 2009. A total number of 375 design teams submitted their applications, and the client/ organiser invited 45 teams of architects. Obviously, the battle for participation was very fierce under such conditions, and only 12 per cent of the architectural firms succeeded in receiving the commission. This is the average number in Sweden for being invited to compete. Through an invitation to prequalification, the organising body - municipalities or governmental agencies - had direct access to a large number of applications made by competent architectural firms, all with fine references and a high reputation within the building sector. The empirical findings are conclusive that this situation leads to the exclusion of young architects or newly established practices.

In the paper, Magnus Rönn makes a critical investigation of the prequalification process based on interviews and analyses of archived documents. In order to be invited, the design teams had to comply with a number of "must have" demands referring to the Swedish Public Procurement Act, the national adaptation of the European Union regulation with the same intent. This is a prerequisite for being allowed to proceed in the evaluation. Thereafter, the professional merits of the candidates are assessed based on various criteria such as design ability, creativity, competence and resources. It is during this evaluation process that the clients'/ organisers' selection committees appoint design teams for participation in restricted competitions. According to Rönn, it is the combination of legal demands and design criteria, developed by the architects' professional practice, that provide the framework for the selection committees.

The second paper, by Professor David Vanderburgh and Carlo Menon, Ph D Fellow, presents a model that is grounded in a case study on professional practice. They use this model for understanding conflicting interests in competitions. The authors have refined this model of the architectural competition and its constitutive elements, since it was first presented at the conference on competitions in Montreal in 2012. The objective was to identify the relationships be- 
tween competing architects and design proposals, means of representation (models, drawings, illustration, texts, and speech), competition rules and the organisers' program (conditions, demands, objectives, evaluation criteria).

The paper is based on a Belgian competition that was held in 2011 to 2012. This competition included an oral presentation of the submitted proposals by the competing design teams in front of the jury board. This is unusual for most competitions, especially for the ones organised in Scandinavian. However, the oral presentation can be an essential moment during the competitive process of parallel commissions among invited architects. A similar type of dialogue between the participants and the client/ the assessors can be found in restricted competitions in Denmark with the ultimate aim of selecting the best possible condition for further design (Competitions rules, section E). Competition rules in Norway, Finland and Sweden require full anonymity during the competition process, both at the design stage and afterwards during the deliberation among the jury members. The entries have to be presented in such a way that the author remains anonymous, often with the names of the authors kept in a sealed envelope. This is a demand in design competitions organized by the public sector, in line with the European Parliament and Council directive (2004/18/EC); this regulation has been transferred into the national legislation of the member countries in Europe.

In the Vanderburgh Menon case study, the competition process was observed from the inside by one of the authors (Menon), who was a that time working for the public agency in charge of the architectural competition. This provides the paper with a unique inside professional perspective of the process. Already at the first meeting, one of the authors became involved in stakeholders' discussion, and thereby contributed indirectly to the writing of the programme and was present during all jury deliberations. The explored competition was a non-anonymous competition. The oral presentations by the competing design teams were documented by means of field notes. In this competition, the translation of the design proposals into words - not only by means of drawings and illustrations - was an essential moment in the process. The architects had to address future users and orally to describe in detail the qualities and how their design solution would contribute to good architecture. The winning team was also the one who was the most able to show the jury board that they were open for discussing the task in the programme. In this case, the rhetoric skills and close attention of the design team to special aspects of the envisioned architecture contributed to convincing the jury of whom to assign as a winner.

Leif Östman, $\mathrm{Ph} \mathrm{D}$, presents an alternative to architectural competitions in the third paper, which ends this issue: the developer competition with a special focus on the development in Helsinki. This is a new type of competition, organised by cities and municipalities in Finland and Sweden, and it has increased in recent years. In this competition, the competing design teams consist of developers or constructors, with a focus on real estate or construction, often in a joint venture with an architectural firm. The winning design proposal can be implemented in two ways; either, the company can buy the site at market price (if the municipality is willing to sell the plot) or the project is realised through a sophisticated leasehold between the municipality and the developer. The developer competition started as an experimental practice during the 1980s, when Finland entered the global economy: The manager of the City of Helsinki Housing Production Department (ATT), Mr. Harri Kauppinen, presented the idea at a seminar. However, it was not a success, and the critics were harsh. But only a few years later, Kauppinen was asked by the head of the ATT to develop the idea in details.

The number of developer competitions in Helsinki organised by the city has grown from a slow pace of one per year to 2-4 developer competitions each year in Helsinki and simultane- 
ously spread to other municipalities and cities in Finland. There are also managerial problems that stem from trials based on a mixture of both quality and price evaluation criteria, where it is much easier to come to an agreement if only one of the criteria is in use. Developer competitions constitute a format that is striving to combine architectural quality, functional performance and construction advantages.

Östman has selected three cases in Helsinki for analysis of the typical content in developer competitions. In these cases, the assessment team was composed of 6-8 people, with one invited independent architect, formally appointed by the public organiser. The design proposals were submitted anonymously. Östman discovered that the competition procedure appeared to be well established, including a productive cooperation between the Planning Department in Helsinki City and the Real Estate Department. The developer competition in Helsinki represents a clear stance of a public administration in a market economy context, where architectural quality is emphasised and the developers/contractors are encouraged to produce appropriate design solutions. Even if the architects often have commercial relations with the clients of developer competitions, and in comparison with architectural competitions, design quality can still be achieved by support of the competition programme, the design solutions by the individual architects and the identification of special features by the assessing jury. There is hope for high-quality architecture in this market-oriented world of competition.

The three papers constitute different contributions that display a richness of research perspectives. They also indicate that there is an on-going process of various changes in the format of architectural and developer competitions. It is important to stress the change away from open competitions with a large number of proposals and the difficulty in managing the prequalification process of invited competitions towards more limited ones. An obvious need materializes that pertains to the analysis of these changes that occur in order to provide clients with solid knowledge about pros and cons of the different competition types. It is the task of the competition research to study these various aspects and to disseminate the conclusions to a broader group of professionals and researchers in Europe and elsewhere. It is important to emphasise the performative capacity of architect competitions and underline their importance as a central institution within the architect's profession and the welfare society: The body of architectural and developer competitions supply examples of best practices within the field of architecture and its development.

Finally we would like to comment on the recurrent use of case studies in the papers as a significant research method in all of the three papers. Without being a simple case of coincidence, we believe that this research strategy is especially well suited for analysing architecture and urban design competitions. In a similar way, research on contemporary competitions consists of cases that architects use in order to expand their own knowledge by studying examples of professional practice. In research, case studies provide a rich story of dynamics and in-depth knowledge. In a persuasive way, Bent Flyvberg (2006) argues that the case study has the ability to produce knowledge of general importance. According to Flyvberg, case study research proves to be both a necessary and a sufficient method for producing scientific results. It is a way of developing knowledge on a phenomenon that holds certain advantages compared to other research methods. As editors, we believe that case studies as a research strategy are especially effective within the field of architecture and urban design. As a result of case study methodology, the three papers presented in this special issue of FORMakademisk present a learning potential. It is our hope that the reader will profit by reading them. In addition, we hope that the three papers are inspirational for other professionals and researchers in order to pursue further research on com- 
petitions in architecture and urban design. Thus, other angles and approaches to the phenomenon can be considered so that the inherent dynamics of architecture competitions can be revealed. The individual reader of the papers of this issue may have another opinion, but it is an open call, let the cases unfold!

Copenhagen-Stockholm-Vasa, March 14th, 2014

Jonas E Andersson, Magnus Rönn, and Leif Östman

Special Issue Editors

\section{Referances}

Flyvberg, B., (2006) Five Misunderstandings About Case-Study Reserach, Qualitative Inquire, 12(2), s. 219-245.Retrieved 3 March, 2012, from doi: 10.1177/1077800405284363

\section{Jonas E Andersson}

Architect and Researcher, PhD

Danish Building Research Institute, SBi, Aalborg University

Email address: jonas3@kth.se

\section{Magnus Rönn}

Architect, Associate Professor, PhD

School of Architecture, Royal Institute of Technology, KTH.

Email address: magnus.ronn@arch.kth.se

\section{Leif Östman}

Architect and Head Teacher, PhD

Construction Engineering, Novia University of Applied Sciences

Email address: leif.ostman@novia.fi 